\title{
Exchange Rate and Inflation Dynamics in a Resource Rich Setting: the Case of Zambia
}

\author{
Lionel Roger, Gregory Smith and Oliver Morrissey*
}

September 2, 2019

\section{Introduction}

As economies become more open to the rest of the world, understanding the effects of global shocks has become an important issue in macroeconomic policy management (Kenourgios and Padhi, 2012; Essers, 2013), and the literature has devoted particular attention to commodity price shocks (Charnavoki and Dolado, 2014; Drechsel and Tenreyro, 2018). For countries in sub-Saharan Africa (SSA), an important concern is the macroeconomic effects of shocks to the commodity they export because many are highly dependent on a specific commodity (Venables, 2016). For example, copper typically accounts for more than $70 \%$ of Zambian export earnings. The aim of this study is to shed light on the interrelationship of export commodity (copper) prices, the exchange rate, and consumer price inflation in the case of Zambia. Zambia is a suitable country to examine in this context for two reasons. First, in late 2015, the countrys currency - the kwacha - experienced a dramatic devaluation of $60 \%$ in just ten weeks, and a rise in consumer prices by about 20\%, just after a sudden rise in copper prices (that had been falling since 2012). Second, Zambia shares key characteristics in this respect with many SSA countries, and - with the usual caveats of external validity - conclusions drawn from this case can be informative beyond the narrow country-specific context. The country has high dependence on one export commodity, copper, the price of which has experienced large fluctuations, and, in 1994, was one of the first of the thirteen SSA countries that had adopted floating exchange rate regimes ${ }^{1}$ by 2016 (IMF, 2016).

Commodity price shocks can have direct effects on the real economy, as the commodity is typically a major production sector (e.g., Drechsel and Tenreyro, 2018), but as far as prices are concerned, the more immediate macroeconomic transmission is through the effect on the exchange rate. The strength of this channel is dominated by the exchange

\footnotetext{
${ }^{*}$ Roger (e-mail: lionel.roger@nottingham.ac.uk) and Morrissey (oliver.morrissey@nottingham.ac.uk): School of Economics, University of Nottingham, University Park, Nottingham NG7 2RD. Smith (email: gregorylbsmith@gmail.com): Renaissance Capital, 50 Bank Street, Canary Wharf London E14 5NT. Lionel Roger's research is supported by the UK Economic and Social Research Council [award number 1511835]. Greg Smith was an employee of the World Bank (Lusaka office) when the research was conducted. He and Lionel Roger are grateful to the World Bank for financial support, and to participants at the Bank of Zambia for comments on a presentation of an early version (published as World Bank Policy Research Working Paper 8128). We are also grateful to anonymous referees for comments.

${ }^{1}$ De jure; as in most of these countries, the de facto classification has changed over time, see Ilzetzki et al. (2017).
} 
rate pass-though to prices (ERPT), that is, the extent to which changes in the exchange rate translate into local price levels. The ERPT tends to be higher in low- and middleincome countries than it is in advanced economies (Ca'Zorzi et al., 2007; Aron et al., 2014), leaving resource-rich low-income countries like those in SSA particularly susceptible to price instability induced by global fluctuations in commodity prices.

Macroeconomic management is difficult under these conditions, starting with the fundamental challenge of choosing the right exchange rate regime. Floating exchange rates and inflation targeting are often advocated, but may not be appropriate for emerging and developing economies (Calvo and Mishkin, 2003), especially with high ERPT (Eichengreen, 2005). Recent research highlights the importance of the choice of exchange rate regime for macroeconomic dynamics (Obstfeld et al., 2017). Irrespective of whether monetary policy targets inflation, the exchange rate, or adopts a hybrid policy, a choice needs to be made as to whether or not the Central Bank should actively anticipate the effects of commodity price fluctuations, given that policy makers face non-trivial trade-offs between long-term and short-term goals. The exchange rate pass-through itself is affected by the inflation environment, with low inflation being associated with a low pass-through (Choudhri and Hakura, 2006; Devereux and Yetman, 2010; Lopez-Villavicencio et al., 2016; Jasova et al., 2016). Avoiding inflation targeting on the grounds of a high ERPT in the short run may then be an obstacle to reducing that same ERPT in the long run. Similarly, the degree to which commodity price shocks affect the exchange rate in the first place may be endogenous to institutional arrangements (Bodart et al., 2015).

Existing literature shows that the price of copper is a key driver of the exchange rate of the kwacha (Bova, 2009; Muhanga et al., 2014; Chipili, 2016). Cashin et al. (2004) test for a long-run relationship between main export commodities and the exchange rate in a sample of 58 countries, and conclude that the Zambian kwacha is indeed a 'commodity currency'. The first stage of our analysis corroborates this finding (we estimate that a $10 \%$ rise in the price of copper leads to an appreciation of the kwacha of about $4 \%$ in the long run). The paper then makes two contributions:

1. Provide new measures of ERPT, based on less restrictive assumptions than previous estimates, to show how changes in the value of the kwacha are reflected in changes in consumer prices (distinguishing food and non-food inflation).

2. Disaggregating the ERPT according to the shock that initially hit the economy to demonstrate that measured ERPT depends on the nature of the shock, with implications for policy responses.

To the best of our knowledge, the only country-specific study explicitly aimed at quantifying the ERPT in Zambia is Zgambo (2015), who estimates it to be relatively high (between $41 \%$ and $49 \%$ ). In estimating the determinants of ERPT in a global sample, Choudhri and Hakura (2006) report a similar value for Zambia (41\% after 4 quarters). Our estimates are substantially lower, ranging from $7 \%$ to about $25 \%$ (depend on the shock). Some literature (Shambaugh, 2008; Forbes et al., 2015) argues that the ERPT need not be the same for all the shocks that drive the exchange rate. A depreciation caused by a drop in commodity prices may translate into local consumer prices to a lesser extent than the same depreciation triggered by expansionary monetary policy.

We identify six shocks to key variables of the Zambian economy (namely shocks to the copper price, external interest rate, output, domestic money supply, exchange rate and inflation) using a combination of sign- and zero-restrictions in the framework of a 
structural vector autoregressive (SVAR) model, estimated on quarterly data from 1995 to 2014. Since Sims (1980), Blanchard and Watson (1986) and Bernanke (1986), the SVAR method has had numerous applications in empirical macroeconomics. The most common identification strategy is the triangular Cholesky decomposition, which implies assumptions that are hard to justify, and the results may be susceptible to the ordering of the variables. Uhlig (2005) suggests the remedy of using economically plausible but less restrictive sign restrictions on the impulse response functions, which can be estimated in a Bayesian VAR. However, Baumeister and Hamilton (2015) show that statistical models that appear to be 'agnostic' at first can in fact be heavily influenced by the priors imposed by the researcher, even if they were originally designed to be uninformative, that is, designed to have little impact on the results. Indeed, they show that there can be situations where results may be driven solely by the priors unintentionally imposed by the researcher. Our approach is guided by this recent literature.

Adopting this more flexible framework allows us to lift a particularly controversial restriction concerning the interaction between inflation and the exchange rate, our key variables of interest. Earlier literature, relying on strictly identified systems of equations, assumed that either the exchange rate would only react to changes in inflation with a delay, or the opposite; either of these assumptions is hard to defend in practice, and where the focus is specifically on the interaction between these two variables imposing such strong a priori assumptions is highly undesirable.

Section 2 discusses relevant aspects of the institutional and historical background and related literature for Zambia. Section 3 presents the methodology and underlying assumptions. Section 4 describes the data, the basic time series properties, and transformations implemented. Section 5 presents the results, that is, the relevant impulse response functions, historical variance decompositions, and estimates of differential ERPTs. Section 6 discusses the turbulence of late 2015, and draws on qualitative evidence in order to explain what led the dynamics discerned earlier in this study to break down. Section 7 concludes.

\section{Background}

Zambia is a small, open commodity-dependent economy and regularly faces challenges from supply shocks. These include shifts in the global copper price, rain-fed agricultural outputs, hydro-electric generation output, and the global price of fuel. It has been a copper producer since prior to independence in 1964, but nationalisation in 1973 and low prices hampered investment in the sector until the 2000s. Fresh investment followed privatisation and higher copper prices in the mid-2000s, supporting a doubling of copper production between 2004 and 2014. The boost to the economy from the copper industry was also complemented by better macroeconomic fundamentals in the 2000s; low inflation by historical standards, and annual GDP growth averaged $7.4 \%$ between 2004 and 2014 . As the production of copper increased and the economy prospered, much larger foreign exchange inflows followed.

The Bank of Zambia states as the primary objective of its monetary policy to maintain price stability and promote financial system stability. Since April 2012, it uses a target policy interest rate as its main instrument, adjusted quarterly in regular times; prior to 2012, monetary policy focussed on monetary aggregates. In 1994, Zambia was one of the first countries in SSA to introduce a floating exchange rate regime, with relatively few and limited interventions to stabilise the exchange rate. 
Figure 1: Key variables from 1995 to 2015 (monthly)
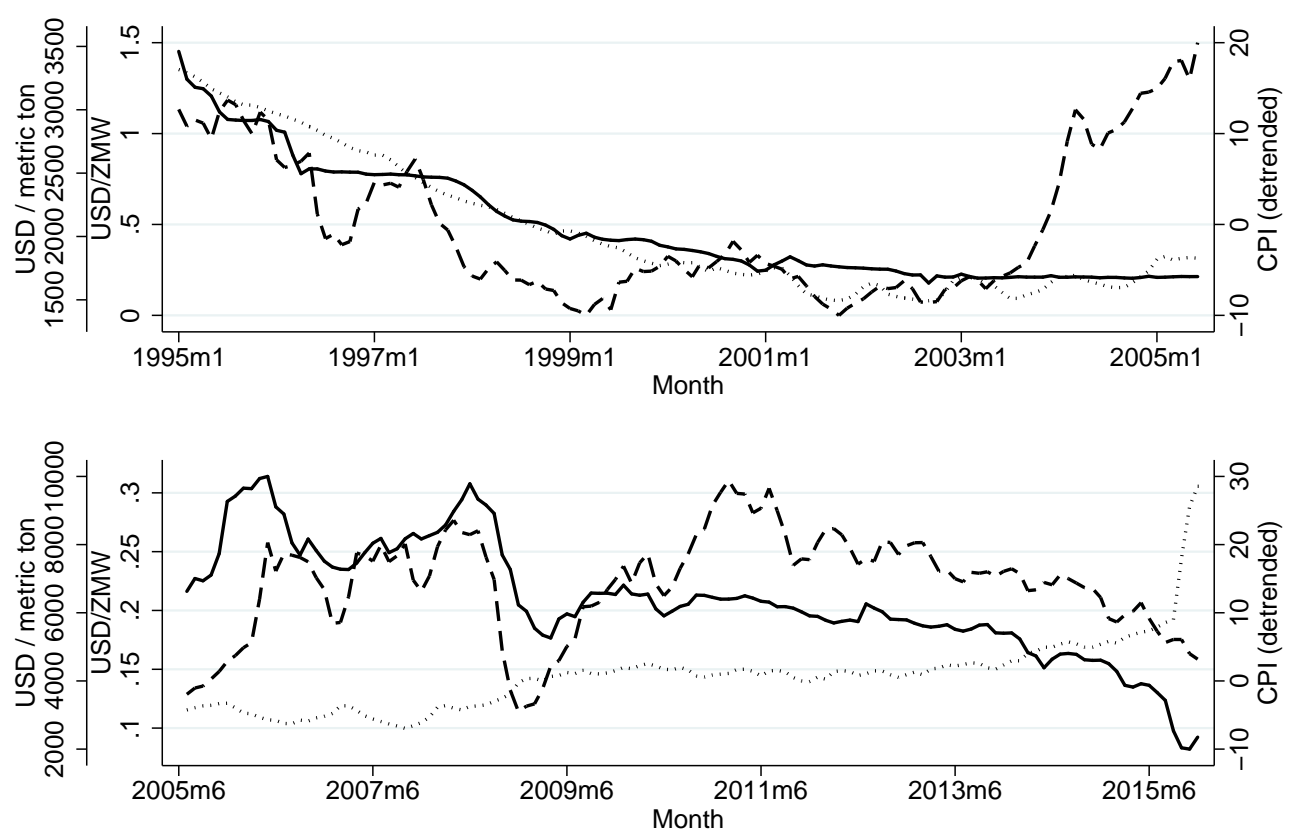

USD/ZMW - - - - USD / metric ton

CPI (detrended)

Between 1994 and 2001, Ilzetzki et al. (2017) classify the Zambian exchange rate regime as a combination of 'freely falling' and 'freely floating', indicating that while the exchange rate has indeed been moving relatively freely, this has sometimes been accompanied by substantial instability. Between 2001 and October 2015, the authors classify Zambia's exchange rate regime as 'de facto band' or 'managed floating', indicating that the country had effectively shifted to a soft peg (to the US Dollar). Following the currency crash in late 2015, the regime is again classified as 'freely falling', and the authors note the presence of a parallel currency market in the aftermath of the crisis. Generally, an important property of Zambia's foreign exchange markets is that they are 'thin', in the sense that there is not much trading, and that they are dominated by few players (notably the large mining firms, the commercial banks, and the Bank of Zambia). There are often times of low trading volume, when large players are not trading and the exchange rate is fairly stable. The participants that are large relative to the level of transactions can exert influence over the exchange rate, sometimes by the timing of their transactions, even if they do not intend to. The experience in 2015 is discussed in Section 6.

Figure 1 traces the key macroeconomic variables relevant to our narrative (the exchange rate, the copper price and consumer prices) since 1995, after the introduction of the floating exchange rate regime in 1994 and at the start of our sample period (see section 4). Before proceeding to the econometric analysis, it is worth relating some of the key changes in the data to the institutional context outlined above. First, notice the changing patterns in the development of the exchange rate (expressed throughout this article in USD/ZMW, such that a decrease corresponds to a depreciation). In the earlier periods (top panel) it seems to be moving rather independently of the copper price (expressed in USD per metric ton). It is only after 2005, when investment and copper production increased, that the two variables began to noticeably move together. 
Second, this coupling coincides with a strong appreciation following scaled-up debt relief under the HIPC initiative in 2005. This appreciation precedes the increase in the copper price around the same time; later it appears the sequence is reversed (changes in the copper price precede those in the exchange rate), consistent with the interpretation that copper became a stronger determinant of the exchange rate after the sector had attracted investment and gained importance. In general, the relationship between the value of the kwacha and the price of copper is now a relatively well established finding (e.g., Muhanga et al. (2014); Pamu (2011) is the only study we know that does not find a relationship between the price of copper and the exchange rate).

Lastly, while consumer prices (CPI) and the exchange rate do generally appear to be trending in the same direction in most periods, prices do not react to exchange rate fluctuations in any obvious manner. This is surprising, as a priori, one would expect a small country with historically high inflation like Zambia to have a large ERPT (Choudhri and Hakura, 2006; Devereux and Yetman, 2010), hence a pronounced co-movement of the two variables. Additionally, the few existing econometric estimates of the ERPT in Zambia would suggest this: both Zgambo (2015) and Choudhri and Hakura (2006) find Zambias ERPT to exceed 40\%. The observation that prices and the exchange rate appear to be largely decoupled does not hold in late 2015, when the sharp depreciation of the currency comes with an increase in inflation (see Section 6).

\section{Methodology}

Subsection 3.1 outlines the general form of the structural VAR employed and discusses the central problem of identifying the relevant shocks. Drawing on Baumeister and Hamilton (2015) and Uhlig (2005), we avoid enforcing a fully identified structure, and instead rely on a combination of sign and zero restrictions to achieve set identification in an underidentified system. This allows us to relax a common, but in our view overly strong (and as our results will show, influential), assumption about the contemporaneous interaction of the exchange rate and inflation. Unlike earlier studies, our specification will allow these variables to contemporaneously affect each other in either direction. As our system is under-identified, estimation will be carried out in a Bayesian framework, which raises the critical issue of selecting sensible priors in a transparent manner (see 3.2).

\subsection{Identification}

We estimate the macroeconomic dynamics of interest in the framework of a vector autoregression of the following form (using the notation of Ramey (2016) and Stock and Watson (2016)):

$$
A(L) Y_{t}=\eta_{t},
$$

where $\eta_{t}$ is a vector of reduced form VAR innovations, that is, the observed residuals as obtained when forecasting $Y_{t}$ based on its lagged values. We make the usual assumptions that these innovations have a zero mean, constant variance, and are uncorrelated with each other. $A(L)$ is a lag polynomial of the form $A(L)=I-\sum_{k=1}^{p} A_{k} L^{k}$, where $L^{k}$ is the lag operator, shifting values by $k$ lags. It effectively applies weights to each lag and element of $Y_{t}$ in order to explain its current values, short of the innovations $\eta_{t}$.

The idea of a structural VAR is specifically to represent $Y_{t}$ in terms of structural shocks $\varepsilon$ that are unexpected, exogenous disturbances to the system, in order to identify 
the effect of unexpected changes in each of the variables, and to subsequently compute parameters of interest such as impulse response functions and variance decompositions. The SVAR assumes that these structural shocks $\varepsilon$ are related to the VAR innovations $\eta$ in the following way:

$$
\eta_{t}=H \varepsilon_{t}
$$

Where the matrix $H$ describes the contemporaneous relationships between the structural shocks $\varepsilon_{t}$ and the reduced form VAR residuals $\eta_{t}$, or how an exogenous shock to any variable will affect each of the variables in $Y$ within the period. We normalize such that the structural shocks have unit effect, that is, diagonal elements are unity (an exogenous shock to any given variable will translate one to one into a change of that same variable). Without any further restrictions however, the system is unidentified, and there exists an infinite number of parameter combinations in $H$ that are equally consistent with the observed data. The challenge is then to impose some structure that will allow us to uncover the parameters of $H$, and therefore the impact of each of the individual shocks onto the system.

This leads us to the critical issue of identification, which sets our study apart from most of the previous literature. Much of this literature relies on a Cholesky decomposition, examples include Muhanga et al. (2014) and Zgambo (2015). For all its benefits (most importantly, pinpointing parameters by just-identifying the system), this comes at the cost of substantial rigidity and requires the researcher to impose strong assumptions on the economic mechanisms that are being investigated. Our approach relies on a combination of sign and zero restrictions in a fashion similar to Uhlig (2005). The general idea is to restrict parameter combinations to the set of those that are consistent with fundamental macroeconomic principles, instead of imposing so many (but potentially unwarranted) restrictions that only one combination remains possible (see section 3.2).

Our system, chosen in line with the literature on exchange rates and inflation, is limited to six variables: the US Federal Funds rate (to represent the external interest rate), the international price of copper, domestic money supply, the domestic output gap, the exchange rate and consumer price inflation (the choice and details of the variables will be discussed in more detail in section 4, and the assumptions underlying this structure later in this section):

$$
\begin{aligned}
\text { Fed }_{t} & =\varepsilon_{F, t} \\
\text { Copper }_{t} & =\phi_{C} F e d_{t}+\varepsilon_{C, t} \\
\text { Money }_{t} & =\phi_{M} \text { Fed }_{t}+\kappa_{M} \text { Copper }_{t}+\varepsilon_{M, t} \\
\text { Output }_{t} & =\phi_{Y} \text { Fed }_{t}+\kappa_{Y} \text { Copper }_{t}+\mu_{Y} \text { Money }_{t}+\varepsilon_{Y, t} \\
\text { ER } & =\phi_{E} \text { Fed }_{t}+\kappa_{E} \text { Copper }_{t}+\mu_{E} \text { Money }_{t}+\nu_{E} \text { Output }_{t}+\pi_{E} \text { Infl }_{t}+\varepsilon_{E, t} \\
\text { Infl }_{t} & =\phi_{P} \text { Fed }_{t}+\kappa_{P} \text { Copper }_{t}+\mu_{P} \text { Money }_{t}+\nu_{P} \text { Output }_{t}+\xi_{P} E R_{t}+\varepsilon_{P, t} .
\end{aligned}
$$

More concisely, we can represent the dynamic behaviour of this system in matrix notation as:

$$
Y_{t}=\Phi(L) Y_{t}+\Omega \varepsilon_{t}
$$

where $\Phi(L)=\Phi_{0}+\sum_{k=1}^{p} \Phi_{k} L^{k}$ : The structural coefficients in system (3) are captured in the contemporaneous matrix $\Phi_{0}$, while the dynamics of additional lags are captured in 
the matrices $\Phi_{k}$. The $\varepsilon$ 's are now the structural shocks we will aim to identify, entering the system as determined by matrix $\Omega$. We follow common practice in assuming that each structural shock only enters one equation, or $\Omega=I$.

As outlined above, our identification strategy will rely on imposing structure on $H$ in order to identify the contemporaneous relationship defined in equation 1 . The specification is similar to a Cholesky decomposition, but relaxes the restrictions on the contemporaneous interactions on inflation and the exchange rate. The combination of sign, indicated by the superscripts ' - ' and ' + ', and zero restrictions takes the form:

$$
H=\left[\begin{array}{cccccc}
1 & 0 & 0 & 0 & 0 & 0 \\
\phi_{F} & 1 & 0 & 0 & 0 & 0 \\
\phi_{M} & \kappa_{M} & 1 & 0 & 0 & 0 \\
\phi_{Y}^{+} & \kappa_{Y} & \mu_{Y} & 1 & 0 & 0 \\
\phi_{E} & \kappa_{E}^{-} & \mu_{E}^{-} & \nu_{E} & 1 & \pi_{E}^{-} \\
\phi_{P} & \kappa_{P} & \mu_{P}^{+} & \nu_{P} & \xi_{P}^{-} & 1
\end{array}\right]
$$

This specification reflects three types of assumptions:

Small economy: The domestic macroeconomic variables in Zambia are assumed to have no contemporaneous impact on the two global variables in the system, the US Federal Funds rate and copper prices. Given the importance of copper as an export in Zambia, the latter may seem restrictive; however, Zambia only accounts for about $2 \%$ of global copper production.

Delayed responses: Monetary policy is assumed to react only with a delay to developments in the economy. In Zambia, the Monetary Policy Committee meets every quarter to review monetary policy, which is also the frequency of our data. Similarly, output is typically observed to react to changes in other variables only with a lag. The ordering implies that output may respond to monetary policy contemporaneously, but not vice versa. Note that a few studies have made the opposite assumption and constrained GDP to only react with a lag based on the argument that it is a notoriously slow variable; in a robustness check, we changed the order and the results were robust to this choice.

Sign restrictions: We impose sign restrictions on contemporaneous parameters where this choice is consistent with a broad range of macroeconomic theories. Specifically, the exchange rate is constrained to depreciate (if anything) as the Fed funds rate increases, as broad money increases, and as domestic inflation increases. Similarly, we constrain the contemporaneous impact of an exchange rate appreciation on prices to be negative or zero, thus excluding parameter combinations that would imply a negative ERPT at impact. Further, the contemporaneous reaction of output to an increase in copper prices is assumed to be positive or zero, as well as that of inflation to an expansionary monetary shock.

\subsection{Priors}

As our system is not fully identified as in the pure Cholesky case, we follow the literature in taking a Bayesian approach in order to estimate the VAR, which requires us to select priors. Baumeister and Hamilton (2015) suggest formulating informative priors directly on parameters with an intuitive economic interpretation, in our case on the contemporaneous 
coefficients in matrix $H$. We follow their approach and use their numerical algorithm to obtain our results. As existing estimates for priors are not available, we estimate the model using a conventional Cholesky decomposition, and feed the estimates as the prior modes into the system described above. Full details are provided in Appendix A.

\section{Data}

We use quarterly data from 1995:2 to 2014:4. This corresponds to a period of relative stability in the Zambian economy, and a regime of flexible exchange rates since 1994. Furthermore, we only have data on the output gap starting from 1995, the first quarter of which drops out as we take first differences. We deliberately exclude the tumultuous year 2015 from the main analysis as it exhibits extreme developments that are likely to dominate and distort our baseline estimations. Instead, section 6 will quantify the discrepancy between the 'usual' dynamics and the episode in 2015 and discuss explanations, pointing at possible avenues for future quantitative research on the topic.

We obtain the price of copper from the IMF's Primary Commodity Price database; the Federal funds rate, the nominal USD/ZMW exchange rate (expressed such that a decrease corresponds to devaluation) and the Zambian CPI from the IMF's International Financial Database; Broad Money (M2) from the Bank of Zambia's fortnightly statistics ${ }^{2}$; and an internal estimate of the output gap kindly provided to us by the Bank of Zambia. All series are originally obtained at a monthly frequency and averaged over quarters, except for the output gap which was provided to us at quarterly frequency.

Figure 2 plots all variables in levels (solid lines) and in log differences (dashed lines). All series, except for the output gap (especially in early periods) resemble non-stationary series; the differenced series however appear stationary. This is confirmed by augmented Dickey-Fuller tests reported in Appendix B (Table A3). As our study focuses on relatively short time horizons, we restrict attention to the differenced series as this is stationary. This transformation is conventional in the literature using structural VAR, as it eliminates the econometric issues associated with non-stationary series such as spurious regression and allows to identify the dynamics associated with the shocks of interest (e.g., Baumeister and Hamilton, 2017). Specifically, we use the log-difference (multiplied by 100) of the copper price, money, the exchange rate and the consumer price index, so as to measure percentage changes between quarters. The Federal Funds rate, already expressed in percentages, will be included in first differences, therefore reflecting changes in percentage points. The output gap is expressed in percentage deviations from potential output and will be included as obtained. Furthermore, we de-trend the consumer price and money series in the usual manner, that is, by regressing a trend term on each of them and retaining the residuals from that equation.

\section{Results}

We discuss our results in three steps. First, we present the basic impulse response functions of our main variables of interest, the exchange rate and inflation. These indicate a strong dependence of the exchange rate on copper, as well as a moderate effect of the exchange rate on price levels (low ERPT). Second, we report variance decompositions over

\footnotetext{
${ }^{2}$ For most of our sample period (until April 2012), the Bank of Zambia used a money supply target, which is why we include M2 rather than the interest rate.
} 
Figure 2: Variables in levels and log differences

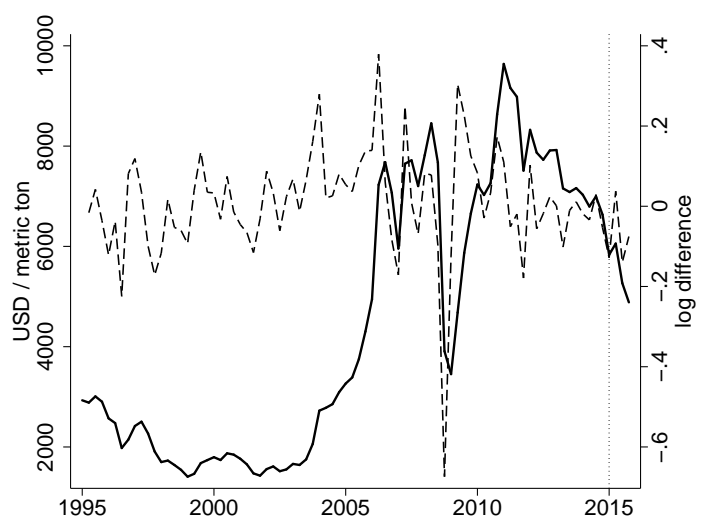

(a) Copper price

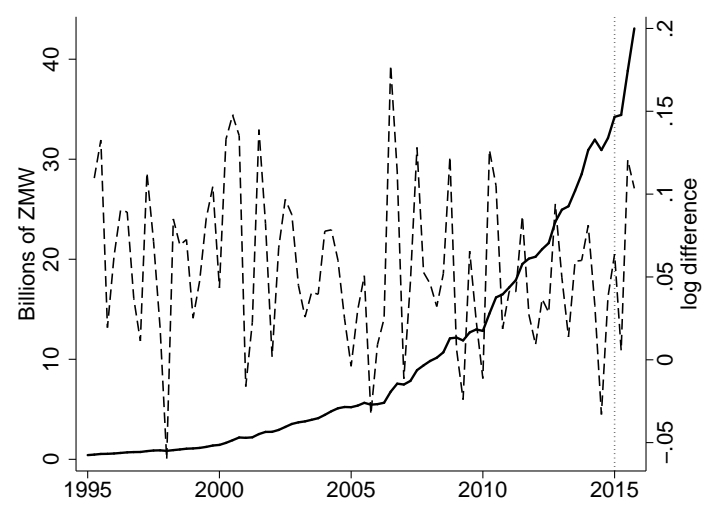

(c) Money (M2)

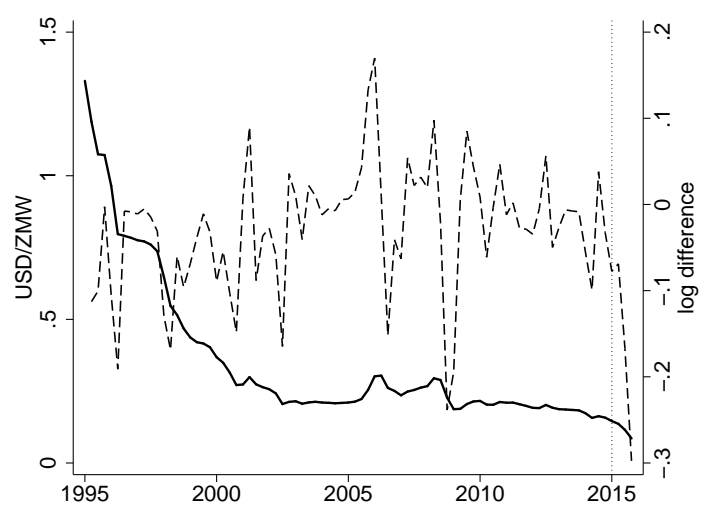

(e) Exchange rate

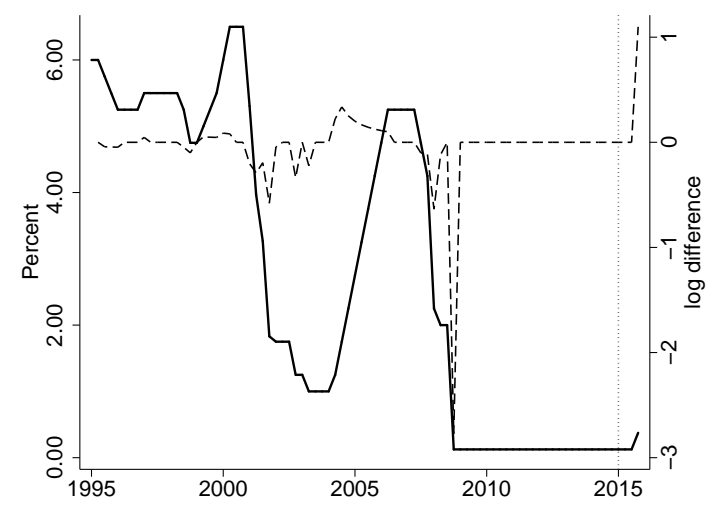

(b) Fed funds rate

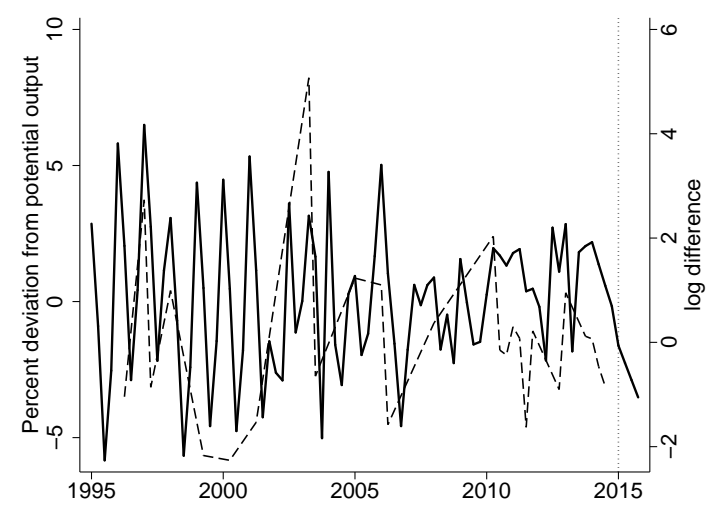

(d) Output gap

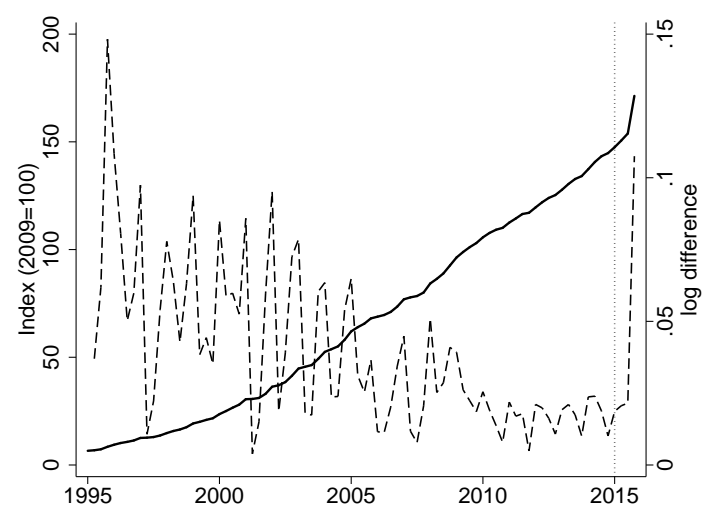

(f) Consumer price index

Notes: The solid lines describe the variables in levels and native units (see left y-axis), the dashed lines indicate the first differences of the logarithm of these series. The dotted vertical line at the beginning of 2015 indicates the end of the sample period used for estimation. See main text for further transformations applied to the series. 
the sample periods in order to isolate the most important contributing factors on each of the variables, and the evolution of this pattern over time. Third, we analyse whether there is a differential ERPT depending on the shock that drives the exchange rate fluctuation, following Forbes et al. (2015). We further investigate whether and to what extent food and non-food inflation are affected differently, and also report differential ERPTs obtained using the respective disaggregated CPIs.

\subsection{Impulse response functions}

Figure 3 depicts the cumulative impulse response functions (IRF) for the exchange rate as a reaction to a $1 \%$ positive shock in the other variables. The solid line reports the pointwise mean IRF, which is the recommended point estimate to report given a linear loss function (Baumeister and Hamilton, 2015). The dashed lines depict the $68^{\text {th }}$ and $90^{\text {th }}$ percentiles of the estimated IRFs (following the Bayesian convention of credible intervals, in lieu of frequentist confidence intervals).

Panel (a) summarizes one of the key results of this exercise: the exchange rate reacts strongly and quickly to an increase in copper prices. The mean response suggests that, at impact (within the quarter), an unanticipated $1 \%$ rise in copper prices leads to an exchange rate appreciation of $0.2 \%$. The exchange rate continues to markedly appreciate for the next two quarters, reaching $0.4 \%$, and then stays at roughly that level. This is slightly lower than the $4.8 \%$ appreciation following a $10 \%$ increase in copper prices in the long run reported by Chipili (2016), although that estimate is within the bounds of the $68 \%$ interval.

An expansionary monetary shock of $1 \%$ (panel (c)) is estimated to induce a marked depreciation of about $0.7 \%$ within the quarter, reaching its peak in the next quarter at $0.9 \%$. The point estimates suggest a slight overshooting here, and the persistent effect is of about $0.8 \%$. Note that after three quarters, the estimates become less confident to the point where a zero effect cannot be excluded based on the $90 \%$ credible interval.

The third most salient driver is domestic prices, reported in panel (e). Although the estimates are too imprecise for clear conclusions, the point estimates suggest a contemporaneous depreciation of about $0.8 \%$ following a $1 \%$ inflationary shock to CPI. The median response suggests a peak depreciation at about $1.4 \%$ after one quarter, which then levels off at about $0.9 \%$ after five quarters. This is evidence that our decision to leave the contemporaneous impact of inflation on the exchange rate unrestricted is well-warranted; restricting it to zero would have forced the intercept of this IRF to be zero, and exerted great but possibly undue effect on ERPT estimates. The effect of the output gap and the Fed funds rate, panels (b) and (d), are ambiguous and estimated with little precision.

Figure 4 is identical in notation and plots the responses of consumer prices to $1 \%$ shocks to any of the other variables. The general picture here is that consumer prices do not react very strongly to the other macro variables, at least based on the short run dynamics analysed in our framework. The most pronounced effect comes from monetary shocks (panel (c)): While a monetary expansion does not have much of an impact contemporaneously, after two quarters, a $1 \%$ monetary shock is estimated to induce a $0.2 \%$ increase in prices.

Panel (e), reporting the response of CPI to a shock in the exchange rate - the ERPT to consumer prices - reveals a very moderate response of consumer prices to changes in the exchange rate based on the short run dynamics. At impact, there is no evidence for an increase in consumer prices. While the precision of the estimate is very low given the 
Figure 3: Responses of the exchange rate to a $1 \%$ shock to key variables

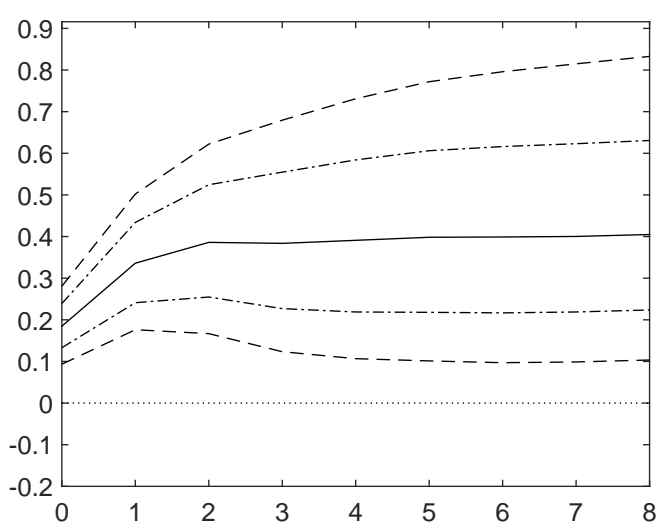

(a) Copper price

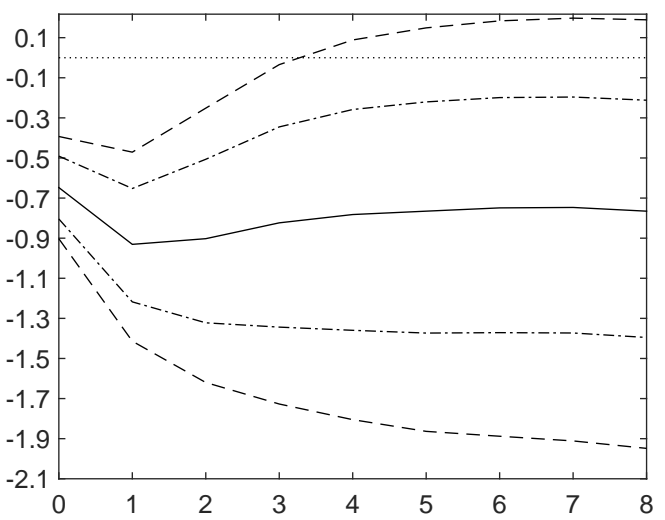

(c) Money (expansionary)

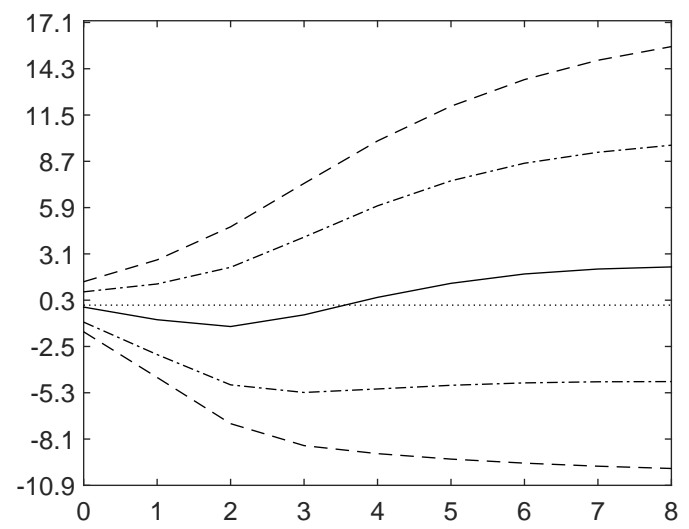

(b) Fed funds rate

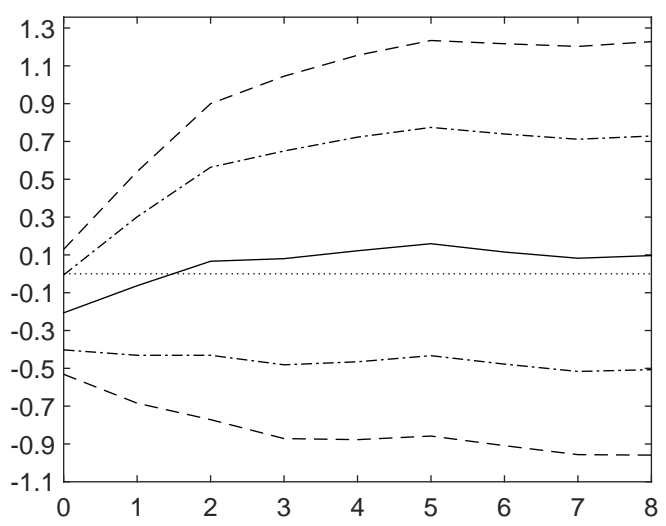

(d) Output gap

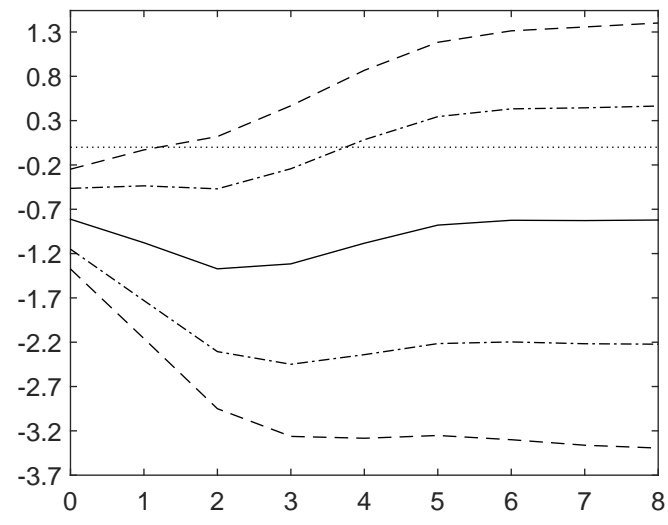

(e) CPI

Notes: The solid line reports the pointwise mean IRF, the dashed lines depict the $68^{\text {th }}$ and $90^{\text {th }}$ percentiles of the estimated IRFs (credible intervals). 
Figure 4: Responses of consumer prices to a $1 \%$ shock to key variables

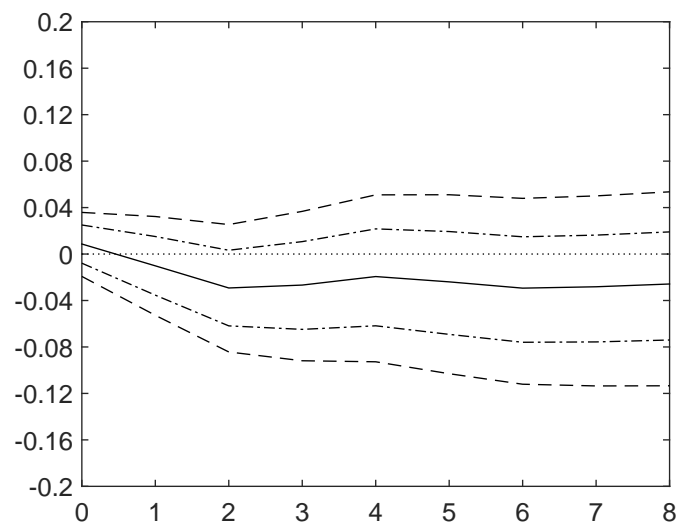

(a) Copper price

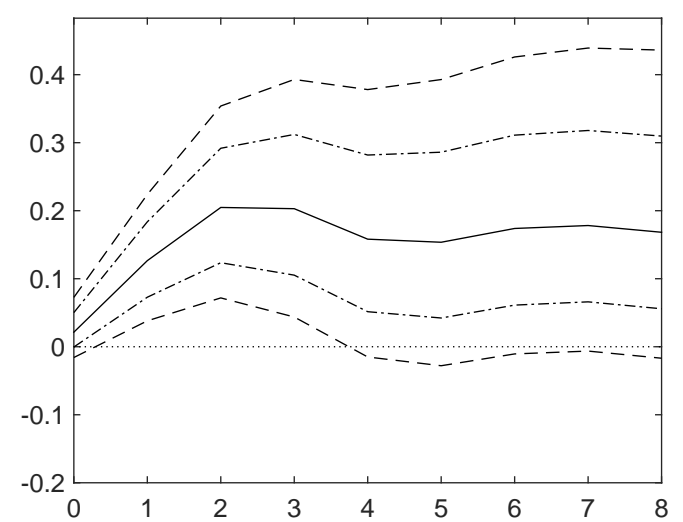

(c) Money (expansionary)

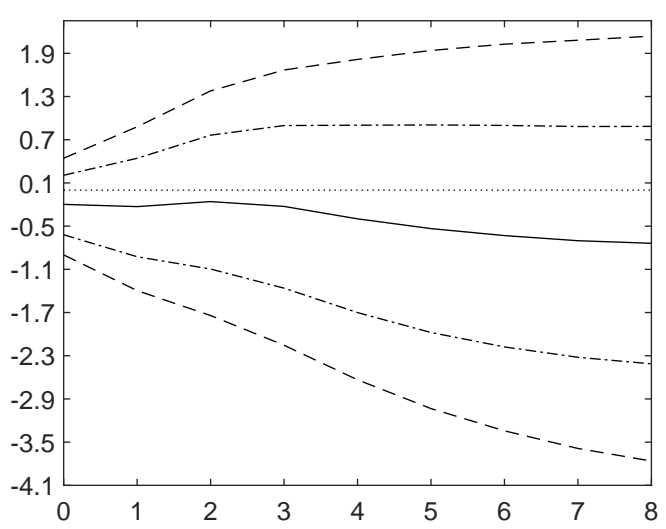

(b) Fed funds rate

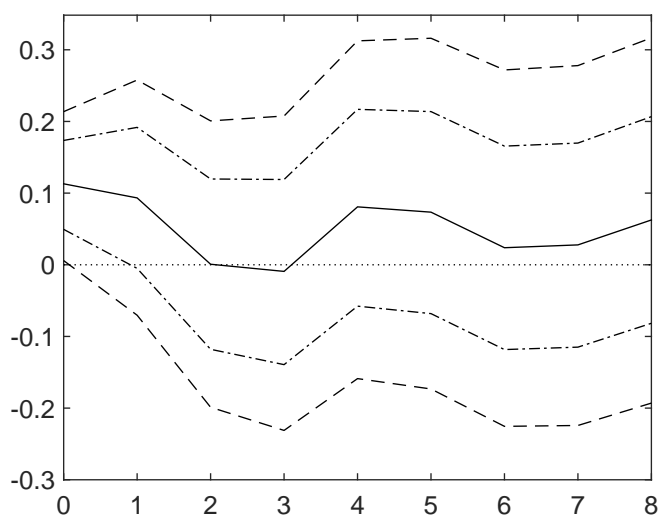

(d) Output gap

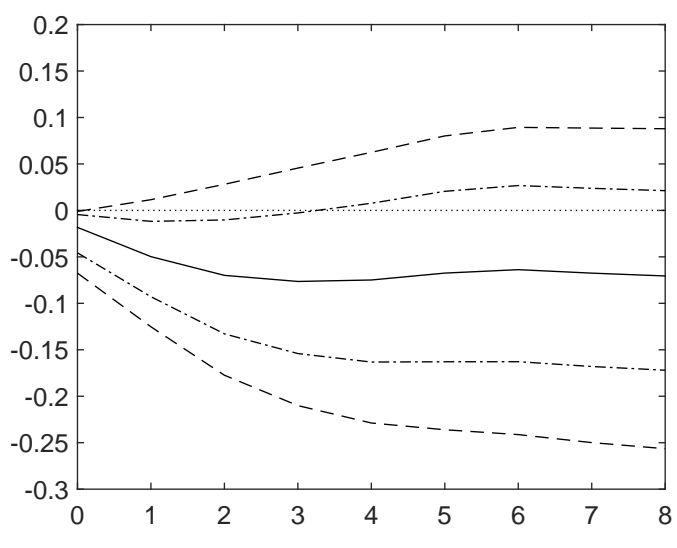

(e) Exchange rate

Notes: The solid line reports the pointwise mean IRF, the dashed lines depict the $68^{\text {th }}$ and $90^{\text {th }}$ percentiles of the estimated IRFs (credible intervals). 
small amplitude of the effect, the median IRF suggests a steady decrease (increase) in prices following an unanticipated appreciation (depreciation) of the exchange rate. The dynamics settle down after four quarters, after consumer prices have decreased (increased) by about $0.07 \%$.

Our estimates therefore imply an ERPT to consumer prices of $7 \%$ after four quarters. This is very low compared to other estimates. The corresponding figures obtained by Zgambo (2015) range between $41 \%$ and $49 \%$, although this is reduced to $20 \%$ when focusing on a more recent period (2004-2014) characterized by lower inflation. Choudhri and Hakura (2006) estimate an ERPT to domestic prices in Zambia of $15 \%$ at impact, and $41 \%$ after four quarters (the corresponding average for developing countries is $24 \%$ ). Besides other important methodological differences in their study, Choudhri and Hakura (2006) study the period 1979-2000 which overlaps with our sample for only five years. The discrepancy is consistent with the main point of their paper: low inflation is associated with a low pass-through (a point that has since frequently been confirmed, see Devereux and Yetman, 2010; Jasova et al., 2016). In our sample period, Zambian inflation is much lower than in earlier decades, averaging $18 \%$ per annum over 1995-2014 compared to 71\% per annum during 1986-2000 (The World Bank, 2016). Our results may therefore reflect a genuine increase in the resilience of the Zambian economy until 2014. A second factor is our decision to leave the initial impact of inflationary shocks on the exchange rate, $\pi_{E}$, unrestricted. Estimating the same set of equations with full identification through a classical Cholesky decomposition $\left(\pi_{E}=0\right.$, no sign restrictions) leads to a higher ERPT estimate of $9 \%$ at impact and about $15 \%$ after four quarters. This is indeed what much of the previous ERPT literature has found, suggesting that some of the results are inflated as causality was constrained to run from exchange rates to prices.

\subsection{Historical decomposition}

Figures 5 and 6 describe the historical contributions of each of the shocks to the changes in the exchange rate and consumer prices, to illustrate the decompositions reported in Table 1. The solid line is the observed value of the respective (de-trended) series, expressed in quarter to quarter changes. The shaded bars indicate the contribution of each of the shocks to this value over the eight periods (two years) prior to the indicated date, computed from the median IRFs discussed in the previous section. As shown in Table 1, besides genuine exchange rate shocks, money supply (M2) and the copper price account for most of the variation in exchange rates, and M2 is usually the more important factor (except for 1996-99 and 2008-11). The role of domestic inflation as a driver of the exchange rate appears to have steadily declined, from $19 \%$ in 1996-99 to $6 \%$ in $2012-14$. The lower panel shows that besides genuine CPI shocks, the output gap, money supply and the copper price account for most of the variation in CPI (their relative importance varies, with M2 generally becoming more important over time).

Figure 5 illustrates these results for the exchange rate and depicts the year by year variation. It is apparent that the factors contributing to exchange rate fluctuations have varied quite substantially over time, but also that the amplitude of the shocks - and therefore that of the exchange rate fluctuations - has declined since about 2009. The graph also offers insights about the nature of individual fluctuations. For instance, the early 2000s saw a number of stark movements in the exchange rate, with money appearing

to be the main driver. The strong appreciation in 2005-06, corresponding to the debt relief under the HIPC initiative, enters mainly as a genuine exchange rate shock. While 
Table 1: Historical variance decomposition of exchange rate and price fluctuations

\begin{tabular}{|c|c|c|c|c|c|c|}
\hline & & $\begin{array}{l}1996 \mathrm{q} 2- \\
1999 \mathrm{q} 4\end{array}$ & $\begin{array}{l}2000 q 1- \\
2003 q 4\end{array}$ & $\begin{array}{l}2004 q 1- \\
2007 q 4\end{array}$ & $\begin{array}{l}2008 q 1- \\
2011 q 4\end{array}$ & $\begin{array}{l}2012 q 1- \\
2014 q 4\end{array}$ \\
\hline \multirow{6}{*}{ 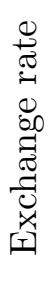 } & Fed & $3 \%$ & $8 \%$ & $9 \%$ & $6 \%$ & $3 \%$ \\
\hline & Copper & $22 \%$ & $13 \%$ & $16 \%$ & $29 \%$ & $15 \%$ \\
\hline & M2 & $15 \%$ & $24 \%$ & $24 \%$ & $20 \%$ & $31 \%$ \\
\hline & Output Gap & $9 \%$ & $10 \%$ & $9 \%$ & $4 \%$ & $6 \%$ \\
\hline & Exchange Rate & $30 \%$ & $32 \%$ & $33 \%$ & $32 \%$ & $40 \%$ \\
\hline & CPI & $19 \%$ & $13 \%$ & $8 \%$ & $8 \%$ & $6 \%$ \\
\hline \multirow{6}{*}{$\overrightarrow{0}$} & Fed & $2 \%$ & $4 \%$ & $5 \%$ & $6 \%$ & $1 \%$ \\
\hline & Copper & $10 \%$ & $6 \%$ & $13 \%$ & $23 \%$ & $14 \%$ \\
\hline & M2 & $7 \%$ & $15 \%$ & $18 \%$ & $20 \%$ & $24 \%$ \\
\hline & Output Gap & $21 \%$ & $21 \%$ & $15 \%$ & $10 \%$ & $21 \%$ \\
\hline & Exchange Rate & $5 \%$ & $3 \%$ & $8 \%$ & $6 \%$ & $6 \%$ \\
\hline & CPI & $55 \%$ & $51 \%$ & $41 \%$ & $35 \%$ & $34 \%$ \\
\hline
\end{tabular}

Notes: The first panel reports the contribution of each variable to the fluctuations of the exchange rate averaged across quarters within five sub-periods. The second panel reports the same information for fluctuations in CPI.

Figure 5: Historical decomposition of changes in the exchange rate (USD/ZWA)

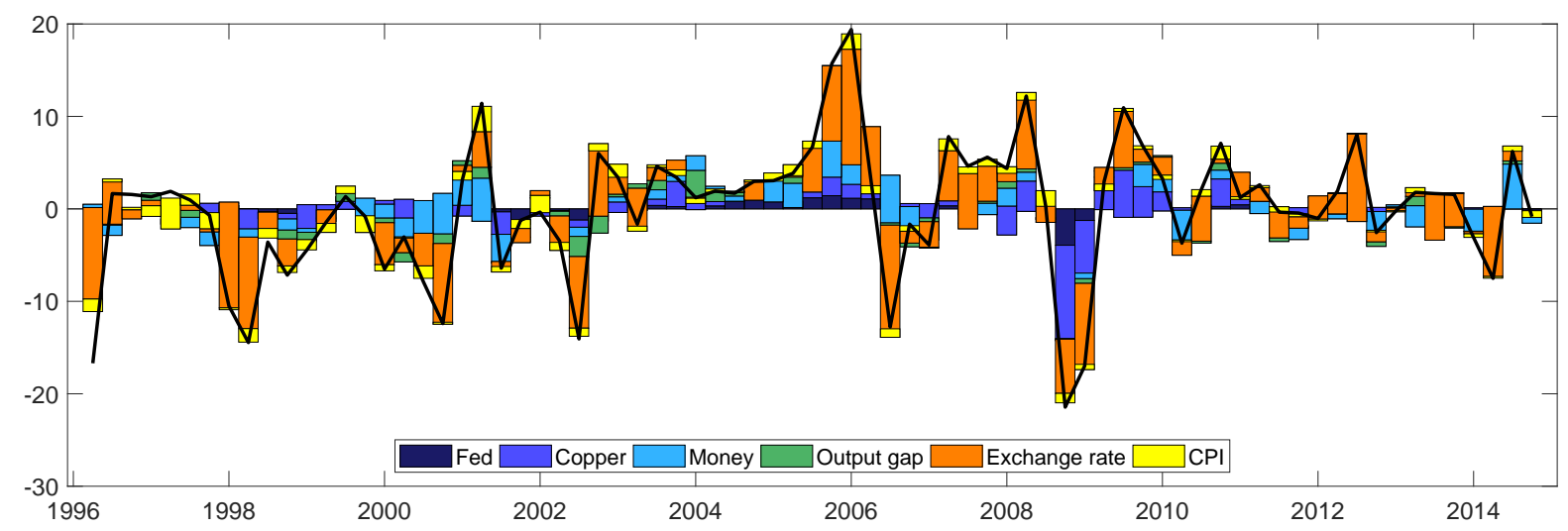

Notes: The black line indicates the values of the exchange rate in log-differences, the bars indicate the contributions of the respective shocks to the respective value based on our estimated parameters. 
Figure 6: Historical decomposition of changes in Zambian consumer prices

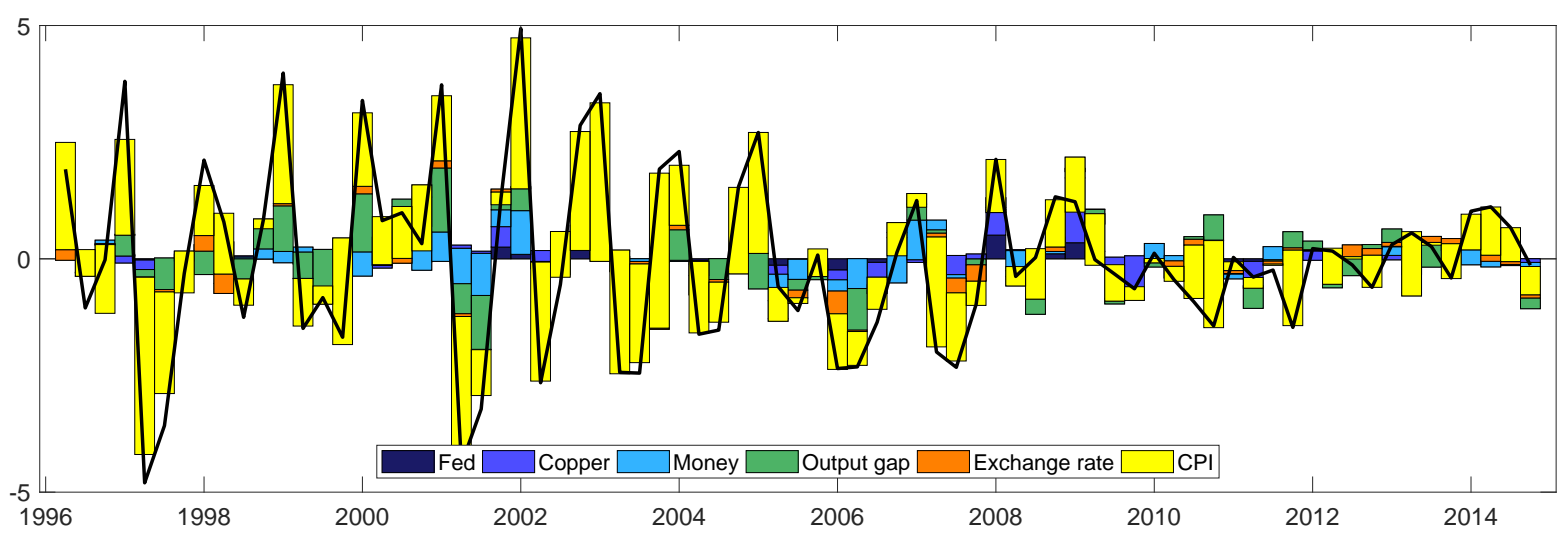

Notes: The black line indicates the values of the CPI in log-differences (de-trended series), the bars indicate the contributions of the respective shocks to the respective value based on our estimated parameters.

the proportional contribution of the price of copper appears rather moderate over much of the sample period, the abrupt depreciation in 2009 illustrates its potential importance, as it accounts for about two-thirds of the variation. The variety of the drivers of these shocks underlines the importance of addressing how the ERPT varies with the underlying economic shock.

Figure 6 decomposes changes in consumer prices in the same way. As expected from the low amplitude of the IRFs presented in section 5.1, the contribution of variables in our system other than CPI itself appear to be relatively limited, and much of the variance is attributed to price shocks that are exogenous to our system. However, fluctuations decline over time, and it is apparent from Table 1 that the role of our macro-variables is increasing towards the end of the period: the role of genuine price shocks steadily decreases from $55 \%$ in 1996-99 to $34 \%$ in 2012-14. A few factors have a notable impact in certain periods. This is the case for the fluctuations in output, especially in periods before 2002. Contractionary monetary shocks contributed to slowdowns in inflation in 2001 and in 2006. While copper prices do not play a prominent role in determining inflation in the first half of the sample period, it becomes more important in the late 2000s. This is plausible, as both copper production as well as prices were significantly higher in later periods (see section 2).

\subsection{Differential exchange rate pass-through}

We will now examine the extent to which different shocks that affect the exchange rate entail different reactions of consumer prices. Our approach is similar to Forbes et al. (2015), in that we use the ratio of the IRF of CPI over the IRF of the exchange rate for a shock to any given variable. These estimates therefore indicate the change in consumer prices induced by a shock that leads to a $1 \%$ appreciation in the exchange rate in any period. The interpretation is then slightly different to the IRFs reported in section 5.1, which traced the effect of a shock that causes a $1 \%$ appreciation at impact (in order for a shock to the copper price to lead to an exchange rate appreciation of $1 \%$ at impact, it needs to have an amplitude of $1 \% / 0.2=5 \%$, see Figure 3). As the shock takes some time to fully affect the exchange rate; a copper price shock that leads to an appreciation of $1 \%$ after four quarters will be smaller than one which such an effect at impact (an amplitude 
Figure 7: Pass through to consumer prices for different shocks

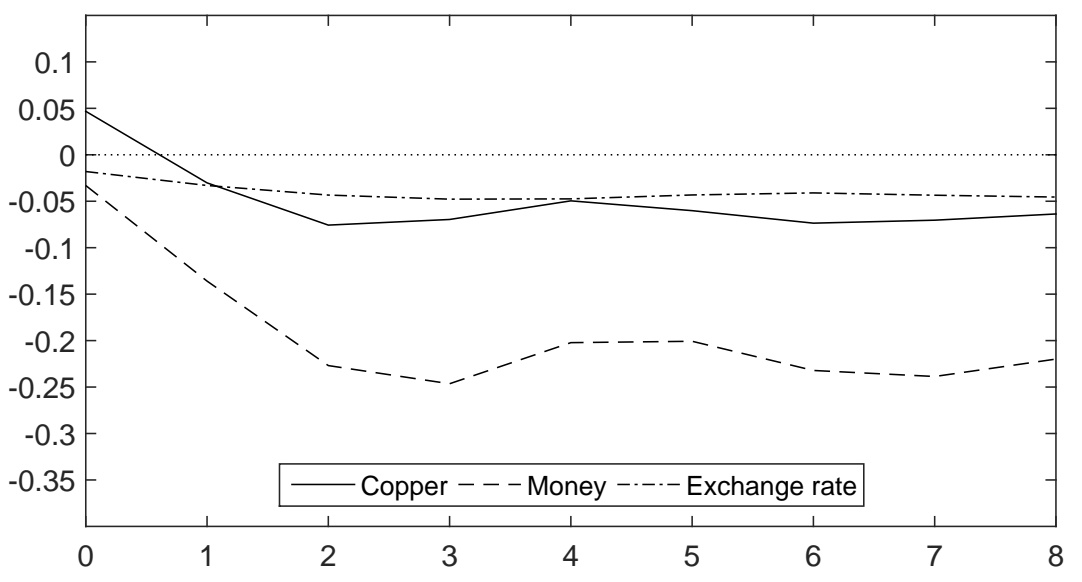

of $1 \% / 0.4=2.5 \%$ ).

Note also that the direction of the original shocks we consider in this section need not be identical to that discussed in section 5.1 when describing the IRFs. Specifically, Figure 7 reports the result of a contractionary monetary shock (reducing inflation), while our previous discussion and Figures 3 and 4 were based on expansionary shocks (increasing inflation). This is because we consider shocks that lead to an exchange rate appreciation, which for money needs to be a contractionary one. Since in section 5.1 we established that both the Fed funds rate and the output gap had little discernible effect on the exchange rate, we focus on shocks to copper prices, money and the exchange rate itself. ${ }^{3}$

Table 2: Pass through for different shocks and time horizons

\begin{tabular}{lrrrr}
\hline Horizon & $\mathbf{0}$ & $\mathbf{1}$ & $\mathbf{4}$ & $\mathbf{8}$ \\
\hline Copper & $5 \%$ & $-2 \%$ & $-5 \%$ & $-6 \%$ \\
Money & $-3 \%$ & $-14 \%$ & $-21 \%$ & $-22 \%$ \\
Exchange rate & $-2 \%$ & $-3 \%$ & $-5 \%$ & $-5 \%$ \\
\hline
\end{tabular}

Figure 7 plots the results. First, note that for a shock to the exchange rate, the effect is even slightly lower than that reported in section 5.1. This is because a shock that raises the exchange rate by $1 \%$ at impact still raises it in the subsequent periods; effectively, Figure 7 refers to smaller exchange rate shocks in all periods after impact. A $1 \%$ increase in the exchange rate caused by a shock to copper prices comes with an increase in consumer prices of $0.05 \%$, implying a negative pass-through at impact of about $-5 \%$. This may reflect aggregate demand effects related to the stimulus to the copper industry (increased employment, rents). The effect is reversed in later periods, with a pass through between $5 \%$ and $8 \%$ in the following quarters. Finally, monetary shocks are associated with by far the strongest pass-though: exchange rate fluctuations that are caused by a monetary shock are estimated to translate into consumer prices with an ERPT of about

\footnotetext{
${ }^{3}$ The latter may seem redundant, as conceptually it is very similar to the exchange rate pass-through already quantified above. Because of calculation in each period, and because an exchange rate shock that raises it by $1 \%$ in the first period may (and does) have a different effect in the second period, it is however not identical.
} 
$25 \%$ after three quarters, with a lasting effect of about $22 \%$. This is particularly relevant in the view of the results from the historical variance decomposition, which indicate that, while the variation of the exchange rate has markedly declined overall, it has recently increasingly been driven by monetary shocks. The remaining exchange rate fluctuations may therefore be disproportionately associated with consumer prices. Note however that this is more than offset by the smaller amplitude of the fluctuations in general.

\subsection{Food versus non-food inflation}

To consider disaggregated effects on inflation, we repeat the analysis separately for the food and non-food CPI (Appendix A Tables A1 and A2 report the priors employed). For the sake of conciseness, we restrict discussion to the differential ERPT. ${ }^{4}$

Figure 8: Differential ERPTs for non-food (top) and food (bottom) inflation
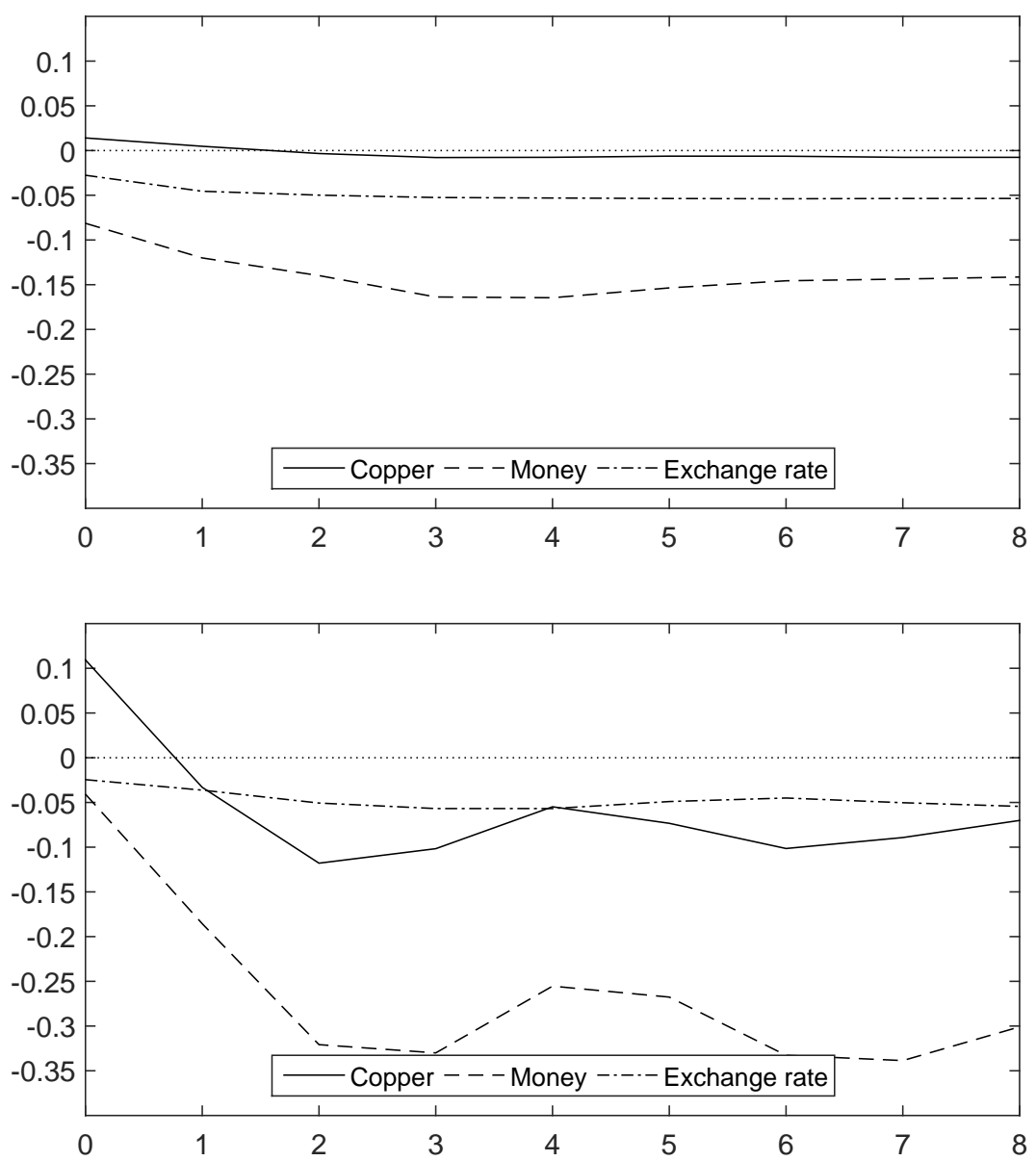

Figure 8 summarizes the differential pass-through results (with interpretation identical to Figure 7). For pure exchange rate shocks, the difference is negligible and both have an ERPT of about $5 \%$. There are marked differences for monetary and copper price shocks. Non-food inflation (top panel) is largely unaffected by exchange rate fluctuations induced by copper price shocks, but exhibits a pass-through of about $15 \%$ for fluctuations driven

\footnotetext{
${ }^{4} \mathrm{~A}$ document containing all the graphs and results for the alternative CPI measures can be found at https://tinyurl.com/y7zyhs5b.
} 
by monetary shocks (compared to nearly $25 \%$ for overall inflation). The disaggregation suggests that the overall pass-through is overwhelmingly driven by food prices (bottom panel): exchange rate fluctuations induced by copper prices come with a pass through of up to $10 \%$, whereas monetary shocks have ERPT up to $33 \%$. This corroborates the finding of a higher ERPT for food items in Zgambo (2015). This may appear puzzling as food items are typically sourced domestically, with most of the labour force working in agriculture on small scale farms with few imported inputs. Possible explanations could be lower menu costs in the informal market for food items, or the fact that processed food items are almost exclusively imported (with an urban bias or a bias towards formal vendors such as supermarkets). This is a question for future research.

\section{Exchange rate and price shocks in 2015}

So far the period after 2015 is excluded because the amplitude of changes would have exerted undue influence on our parameter estimates. Having established the dynamics in arguably normal times, we conclude by quantifying the extent to which the variables deviated from their econometrically expected behaviour in late 2015, computing the predicted values for each period up to 2015, extending beyond the original sample period using the parameters derived from it.

Figure 9 plots the predicted series against the observed values since 2009. In the first six years, the difference for exchange rate fluctuations is on average below 4 percentage points (top panel). However, the model fundamentals fail to predict or explain the massive depreciation in late 2015. For the last quarter of 2015, the predicted depreciation of $7 \%$ contrasts with the actual depreciation of almost 30\%, a discrepancy of 23 percentage points. An even more striking discrepancy arises between the observed and predicted CPI series (bottom panel). Mainly due to a general economic downturn, as captured in the Output gap, that counteracts the inflationary pressures arising from the depreciation, consumer prices (adjusted for the trend) were expected to stay stable (-0.1\%) according to the model in the last quarter of 2015. Instead, monthly inflation shot up by an unexpected $9.6 \%$.

These discrepancies point towards dynamics that are substantially out of the ordinary, taking the preceding two decades as a benchmark. In view of the abruptness and peculiarity of the events, it should be emphasized that a narrative case study is needed in order to understand the mechanisms that led up to the sweeping currency depreciation and price inflation. While not our focus, we highlight some key aspects that future research should seek to explore. Discussions with policy makers and private stakeholders suggested the following aspects were key in understanding the abrupt currency depreciation:

Thin market: The currency market in Zambia is very thin and dominated by a few large players, most notably mining companies, the central bank, and some private banks. Individual transactions can have a great weight in the determination of the market exchange rate, something that is perpetuated as such transactions work as a signal for other market participants.

Trade deficit: In December 2014, Zambia's balance of trade turned negative after nearly a decade of surpluses. In the first half of 2015, there was a widespread apprehension among currency traders that the negative trade balance would persist or worsen. 
Figure 9: Predicted and observed changes in exchange rate and CPI

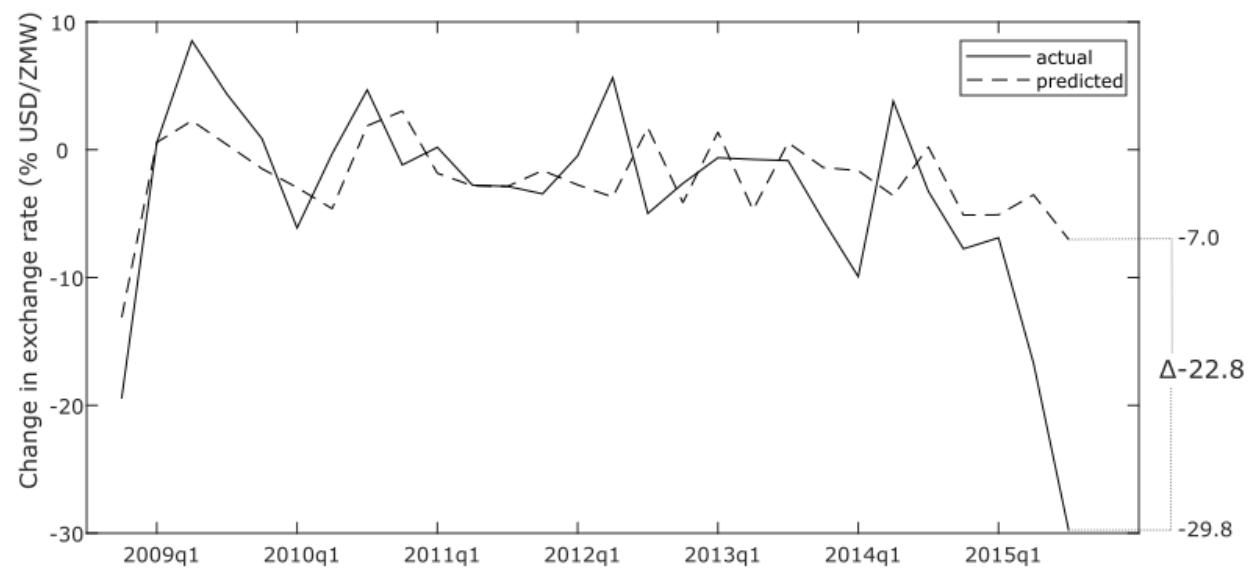

(a) Predicted exchange rate

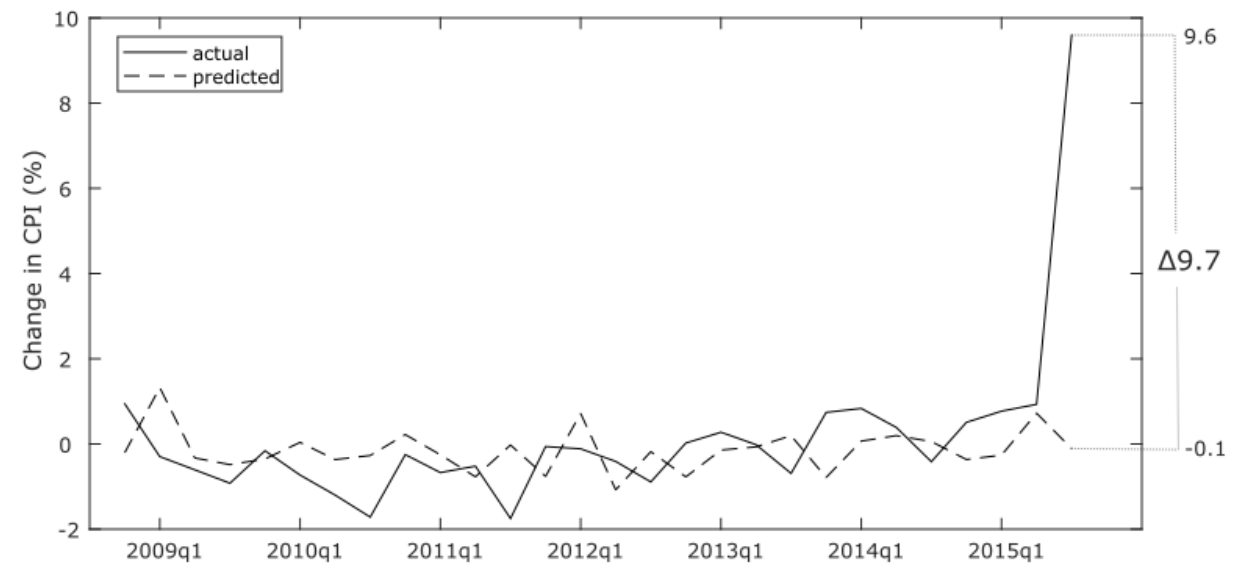

(b) Predicted CPI

This was confirmed by the government in late August, inducing a sharp and sudden depreciation.

Breakdown of price revealing mechanisms: In an attempt to limit speculative and panic behavior, authorities closed the conventional foreign exchange market, where offers could openly be published and observed by participants. Contrary to the original intention, this effectively led to a breakdown of price revealing mechanisms and nurtured suspicions among market participants that authorities were artificially keeping the exchange rate from dropping to its 'true' value. This turned into a self-fulfilling prophecy, and the actual rate consequently dropped to excessively low levels, reaching a low of 14 
ZMW/USD on November 10.

Delayed policy response: The Bank of Zambia maintained a passive monetary policy at first. In the face of deteriorating conditions, the authorities substantially tightened monetary policy in mid-November; the exchange rate rapidly stabilised, as did inflation.

The fact that consumer price inflation increased in line with the exchange rate depreciation during this episode may seem at odds with the finding of a relatively low overall ERPT, especially as the exchange rate fluctuations were not driven by monetary shocks. This may be due to a number of factors. First, the currency crisis coincided with poor harvests in the agricultural sector, independently driving food price increases. Second, large changes in the exchange rate may translate into prices differently to small changes (Aron et al., 2014; Jasova et al., 2016): menu costs may imply that producers and retailers absorb small changes through their profit margins, and will only adjust prices once a certain threshold has been surpassed (such as in late 2015); and, in times of large fluctuations, retailers pay increased attention to the exchange rate and adjust prices at a higher frequency, ${ }^{5}$ mechanically leading to a complete ERPT for these transactions.

\section{Conclusions}

The paper investigated the dynamics of the exchange rate and its interaction with consumer prices in Zambia in a structural VAR framework, identifying shocks with a combination of theoretically plausible zero and sign restrictions. Crucially, we imposed minimal restrictions on the interaction between the two key variables (inflation and the exchange rate), which sets our study apart from the earlier literature. Building on recent developments, we explored the possibility of differential exchange rate pass-through depending on which shock originally caused the exchange rate to fluctuate. To the best of our knowledge, we are the first to do so in the context of a commodity dependent low-income country. Finally, we contrasted model predictions with the tumultuous period of late 2015, and outlined the key aspects that led to the collapse of 'normal' macroeconomic relationships.

Our findings suggest that the pass through from the exchange rate to consumer prices is relatively moderate for pure exchange rate shocks; a 10\% depreciation induces an increase in consumer prices of $0.7 \%$ after one year, corresponding to an ERPT of $7 \%$. This is substantially less than other studies typically find for small, low income countries, and far below the estimates of over $40 \%$ for Zambia by Zgambo (2015), and Choudhri and Hakura (2006). This is likely due to two factors. First, unlike much of the comparable literature, we do not impose any directionality on the contemporaneous relationship between the exchange rate and inflation. When doing so, our estimates of the ERPT are more than doubled. Second, we study a recent period when Zambia maintained a fairly low level of inflation by historical standards. It is an established finding that countries with lower inflation typically have a smaller ERPT, and Zambia may indeed have successfully reduced its vulnerability to global shocks in this respect. From a policy perspective, this result supports the view that 'fear of floating' is - in times of normal market conditions not warranted in Zambia, as resilience to exchange rate shocks appears to be larger than

\footnotetext{
${ }^{5}$ Anecdotal evidence suggests that this was the case during 2015, with some retailers informally declaring prices in USD, and converting them into kwachas based on the daily exchange rate for every purchase.
} 
commonly believed (late 2015 may be 'the exception that proves the rule'). It appears that the Bank of Zambia's commitment to keeping inflation at moderate levels was effective and should be maintained.

Variance decomposition shows that the main drivers of exchange rate fluctuations are copper prices and the money supply. While the copper price can be an influential factor, it only becomes salient episodically. While money supply has typically accounted for the largest share of exchange rate fluctuations, the influence of copper is concentrated in individual periods of large price volatility; most notably, it accounts for the largest share of the devaluations in the period from 2008 to 2011. As inflation declined throughout the sample period, so did its importance in the determination of the exchange rate.

We further investigated whether the ERPT varies with the shock that initially caused the exchange rate to fluctuate. Our findings suggest that exchange rate fluctuations caused by copper shocks behave very much like pure exchange rate shocks in that they are associated with an ERPT of only 7\%. In terms of consumer price stability, the copper price should therefore not be considered a major concern. This result supports the view that trying to anticipate the effect of commodity price shocks using monetary policy is best avoided. Fluctuations due to monetary shocks, on the other hand, are associated with a much larger pass-through of up to $25 \%$ ( $22 \%$ in the long run). When considering only food inflation, this figure is even higher at up to $33 \%$. Monetary interventions aimed at stabilising the exchange rate therefore have disproportionately large simultaneous effects on consumer prices, once more supporting a rather passive monetary policy with respect to the exchange rate. Where the goal is to maintain price stability, interventions should target this objective directly, and not seek to offset exchange rate fluctuations.

Lastly, we note that the sharp depreciation of the exchange rate, as well as the steep increase in consumer prices in late 2015 cannot be explained from the underlying fundamentals included in our system. Instead, we suggest a narrative of market panic paired with non-linearities in the ERPT, and outline the core aspects: thin markets, a deteriorating balance of trade, the breakdown of price revealing mechanisms, and a delayed policy response. This suggests the importance of responding quickly to exogenous exchange rate shocks and calming markets. 


\section{References}

Aron, J., Macdonald, R., and Muellbauer, J. (2014). Exchange rate pass-through in developing and emerging markets: A survey of conceptual, methodological and policy issues, and selected empirical findings. Journal of Development Studies, 50(1):101-143.

Baldini, A., Benes, J., Berg, A., Dao, M. C., and Portillo, R. (2012). Monetary policy in low income countries in the face of the global crisis: The case of Zambia. IMF Working Paper, $(19 / 94)$.

Baumeister, C. and Hamilton, J. D. (2015). Sign restrictions, structural vector autoregressions, and useful prior information. Econometrica, 83(5):1963-1999.

Baumeister, C. J. and Hamilton, J. D. (2017). Structural interpretation of vector autoregressions with incomplete identification: Revisiting the role of oil supply and demand shocks. NBER Working Paper, (24167).

Bernanke, B. S. (1986). Alternative explanations of the money-income correlation. In Carnegie-Rochester conference series on public policy, volume 25, pages 49-99. Elsevier.

Blanchard, O. J. and Watson, M. W. (1986). Are business cycles all alike? In Gordon, R. J., editor, The American business cycle: Continuity and change, pages 123-180. University of Chicago Press.

Bodart, V., Candelon, B., and Carpantier, J.-F. (2015). Real exchanges rates, commodity prices and structural factors in developing countries. Journal of International Money and Finance, 51:264-284.

Bova, E. (2009). Is the Zambian Kwacha a commodity currency? The co-movement between copper prices and the exchange rate. NCCR Trade Regulations SWISS National Centre of Competence in Research Working Paper, (2009/11).

Calvo, G. A. and Mishkin, F. S. (2003). The mirage of exchange rate regimes for emerging market countries. Journal of Economic Perspectives, 17(4):99-118.

Cashin, P., Céspedes, L. F., and Sahay, R. (2004). Commodity currencies and the real exchange rate. Journal of Development Economics, 75(1):239-268.

Ca'Zorzi, M., Hahn, E., and Sánchez, M. (2007). Exchange rate pass-through in emerging markets. ECB Working Paper Series, (739).

Charnavoki, V. and Dolado, J. J. (2014). The effects of global shocks on small commodityexporting economies: lessons from canada. American Economic Journal: Macroeconomics, 6(2):207-37.

Chipili, J. M. (2016). Copper price and exchange rate dynamics in Zambia. Journal of International Development, 28(6):876-886.

Choudhri, E. U. and Hakura, D. S. (2006). Exchange rate pass-through to domestic prices: does the inflationary environment matter? Journal of International Money and Finance, 25(4):614-639. 
Devereux, M. B. and Yetman, J. (2010). Price adjustment and exchange rate pass-through. Journal of International Money and Finance, 29(1):181-200.

Drechsel, T. and Tenreyro, S. (2018). Commodity booms and busts in emerging economies. Journal of International Economics, 112:200-218.

Eichengreen, B. (2005). Can emerging markets float? Should they target inflation. In R. Driver, C. T. and Sinclair, P., editors, Exchange Rates, Capital Flows and Policy, chapter 8, pages 149-175.

Essers, D. (2013). Developing country vulnerability in light of the global financial crisis: Shock therapy? Review of Development Finance, 3(2):61-83.

Forbes, K. J., Hjortsoe, I., and Nenova, T. (2015). The shocks matter: improving our estimates of exchange rate pass-through. MIT Sloan Research Paper, (5149-15).

Ilzetzki, E., Reinhart, C. M., and Rogoff, K. S. (2017). Exchange arrangements entering the 21st century: Which anchor will hold? NBER Working Paper, (w23134).

IMF (2016). Annual report on exchange arrangements and exchange restrictions 2016. Technical report, International Monetary Fund.

Jasova, M., Moessner, R., and Takats, E. (2016). Exchange rate pass-through: what has changed since the crisis? BIS Working Papers, (583).

Kenourgios, D. and Padhi, P. (2012). Emerging markets and financial crises: regional, global or isolated shocks? Journal of Multinational Financial Management, 22(1-2):2438 .

Lopez-Villavicencio, A., Mignon, V., et al. (2016). Exchange rate pass-through in emerging countries: Do the inflation environment, monetary policy regime and institutional quality matter? CEPII Working Paper, 7.

Muhanga, I., Zyuulu, I., and Adam, C. (2014). Monetary policy and the exchange rate in Zambia. In Christopher Adam, Paul Collier, M. G., editor, Zambia: Building Prosperity from Resource Wealth, pages 110-128. Oxford University Press.

Obstfeld, M., Ostry, J. D., and Qureshi, M. S. (2017). A tie that binds: revisiting the trilemma in emerging market economies. IMF Working Paper, (17/130).

Pamu, E. M. (2011). Does the copper price explain the deviation of the real exchange rate from the purchasing power parity equilibrium in zambia. Issues on the Zambian Economy, 1(6):38-44.

Ramey, V. A. (2016). Macroeconomic shocks and their propagation. In Taylor, J. B. and Uhlig, H., editors, Handbook of Macroeconomics, volume 2, pages 71-162. Elsevier.

Shambaugh, J. (2008). A new look at pass-through. Journal of International Money and Finance, 27(4):560-591.

Sims, C. A. (1980). Macroeconomics and reality. Econometrica, 48(1):1-48. 
Stock, J. H. and Watson, M. W. (2016). Dynamic factor models, factor-augmented vector autoregressions, and structural vector autoregressions in macroeconomics. In Taylor, J. B. and Uhlig, H., editors, Handbook of Macroeconomics, volume 2, pages 415-525. Elsevier.

The World Bank (2016). World Development Indicators, retrieved 12 March, 2016.

Uhlig, H. (2005). What are the effects of monetary policy on output? Results from an agnostic identification procedure. Journal of Monetary Economics, 52(2):381-419.

Venables, A. J. (2016). Using natural resources for development: why has it proven so difficult? Journal of Economic Perspectives, 30(1):161-84.

Zgambo, P. (2015). Exchange rate pass-through to domestic prices in Zambia. The BoZ Reader, 2(1):28-55. 


\section{APPENDIX}

\section{A Constructing Priors}

The fundamental challenge is finding sensible prior values for the SVAR, that is, expectations about the values of the contemporaneous elasticities between the variables included in our system. It was not possible to base all our priors on results of the earlier literature, for a number of reasons. It is not common for the empirical literature to report the contemporaneous coefficients making up the matrix $H$, e.g., Muhanga et al. (2014) only report impulse response functions, and thus do not offer a starting point for our priors. The size of the VAR complicates the search as we estimate 16 contemporaneous parameters, for which few have estimates of priors applicable to Zambia. Furthermore, there provides little guidance; Baldini et al. (2012) develop a DSGE model to analyse monetary policy in Zambia none of the macro-parameters of interest here correspond to those employed in their model.

In order to obtain sensible priors, we start by estimating the model using a conventional Cholesky decomposition, thereby obtaining results based on more restrictive assumptions as typically made in the earlier literature. We then feed the resulting estimates as the prior modes into the system described earlier, using the algorithms to improve them. Given the structure, it is not possible to estimate priors for $\pi_{E}$ and $\zeta_{P}$ simultaneously. In order to obtain prior modes for both, we estimate the system twice, once as described above, and then reversing the order of the last two variables (exchange rate and inflation). All other parameters are those obtained from the estimation with the order exchange rate before inflation. Following Baumeister and Hamilton (2015), we formulate the priors on the parameters in $\mathrm{H}$ as student $t$ distributions with three degrees of freedom, and a scale parameter of 0.6, reflecting moderate confidence in our prior modes. Table A1 explicitly reports the prior modes. The posteriors are then obtained from running a MetropolisHastings algorithm with $2 \times 10^{6}$ repetitions, $5 \times 10^{5}$ of which are stored (that is, $1.5 \times 10^{6}$ iterations serve as a burn-in period). ${ }^{6}$ Table A1 reports the prior modes, Table A2 reports the posterior modes. The tables also reports the priors for the analysis of food and nonfood CPI categories discussed in section 5.4.

\footnotetext{
${ }^{6}$ Baumeister and Hamilton (2015) keep $1 \times 10^{6}$ repetitions for their posterior distribution; for a lack of computational capacity (working memory), we constrained ourselves to half that number.
} 
Table A1: Prior values of contemporaneous matrix $H$

\begin{tabular}{llcccccc}
\hline & & \multicolumn{7}{c}{ Shock } \\
\hline Fed & CPI type & Fed & Copper & Money & Output & Exch. rate & Price \\
funds & All & & & & & & \\
rate & Non-Food & 1 & 0 & 0 & 0 & 0 & 0 \\
& Food & & & & & & \\
Copper & All & 8.52 & & & & & \\
& Non-Food & 9.42 & 1 & 0 & 0 & 0 & 0 \\
& Food & 8.53 & & & & & \\
M2 & All & -2.65 & -0.04 & & & & \\
& Non-Food & -2.53 & -0.04 & 1 & 0 & 0 & 0 \\
& Food & -2.47 & -0.04 & & & & \\
Output & All & -0.49 & $\mathbf{0 . 0 3}$ & -0.02 & & & \\
Gap & Non-Food & 0.05 & $\mathbf{0 . 0 3}$ & -0.03 & 1 & 0 & 0 \\
& Food & -0.64 & $\mathbf{0 . 0 4}$ & 0 & & & \\
\multirow{2}{*}{ Exchange } & All & $\mathbf{- 1 . 7 7}$ & 0.21 & $\mathbf{- 0 . 7 6}$ & 0.28 & & $\mathbf{- 0 . 8 5}$ \\
rate & Non-Food & $\mathbf{- 2 . 9 8}$ & 0.22 & $\mathbf{- 0 . 7 9}$ & 0.16 & 1 & $\mathbf{- 1 . 3}$ \\
& Food & $\mathbf{- 1 . 6 7}$ & 0.18 & $\mathbf{- 0 . 7 7}$ & 0.34 & & $\mathbf{- 0 . 4 7}$ \\
\hline \multirow{2}{*}{ Inflation } & All & -0.11 & 0.02 & -0.07 & 0.04 & $\mathbf{- 0 . 0 9}$ & \\
& Non-Food & 0.25 & 0.02 & -0.04 & 0.05 & $\mathbf{- 0 . 1 1}$ & 1 \\
& Food & -0.55 & 0.03 & -0.11 & 0.08 & $\mathbf{- 0 . 0 9}$ & \\
\hline
\end{tabular}

Notes: Priors reported in bold are subject to a sign restriction. The respective sign can be inferred from the reported value of the prior. The priors are obtained from just-identified Cholesky decompositions as described in section 3.1. 
Table A2: Posterior values of contemporaneous matrix $H$

\begin{tabular}{|c|c|c|c|c|c|c|c|}
\hline & & \multicolumn{6}{|c|}{ Shock } \\
\hline & CPI type & Fed & Copper & Money & Output & Exch. rate & Price \\
\hline Fed funds rate & $\begin{array}{l}\text { All } \\
\text { Non-Food } \\
\text { Food }\end{array}$ & 1 & 0 & 0 & 0 & 0 & 0 \\
\hline Copper & $\begin{array}{l}\text { All } \\
\text { Non-Food } \\
\text { Food } \\
\text { All }\end{array}$ & $\begin{array}{c}8.19 \\
9.51 \\
9.19 \\
-3.07\end{array}$ & 1 & 0 & 0 & 0 & 0 \\
\hline M2 & $\begin{array}{l}\text { Non-Food } \\
\text { Food } \\
\text { All }\end{array}$ & $\begin{array}{l}-2.19 \\
-2.48 \\
-0.03\end{array}$ & $\begin{array}{l}-0.09 \\
-0.05 \\
0.01\end{array}$ & 1 & 0 & 0 & 0 \\
\hline Output Gap & $\begin{array}{l}\text { Non-Food } \\
\text { Food } \\
\text { All }\end{array}$ & $\begin{array}{c}0.41 \\
-0.28 \\
\mathbf{- 2 . 4 5}\end{array}$ & $\begin{array}{l}\mathbf{0 . 0 1} \\
\mathbf{0 . 0 0} \\
\mathbf{0 . 0 1} \\
0.18\end{array}$ & $\begin{array}{l}-0.08 \\
-0.14 \\
-\mathbf{0 . 6 8}\end{array}$ & $\begin{array}{c}1 \\
-0.09\end{array}$ & 0 & $\begin{array}{c}0 \\
-\mathbf{0 . 8 2}\end{array}$ \\
\hline Exchange rate & $\begin{array}{l}\text { Non-Food } \\
\text { Food }\end{array}$ & $\begin{array}{l}-2.53 \\
-1.80\end{array}$ & $\begin{array}{l}0.16 \\
0.17\end{array}$ & $\begin{array}{l}-0.86 \\
-0.67\end{array}$ & $\begin{array}{l}-0.03 \\
-0.34\end{array}$ & 1 & $\begin{array}{l}-0.65 \\
-0.97\end{array}$ \\
\hline Inflation & $\begin{array}{l}\text { All } \\
\text { Non-Food } \\
\text { Food }\end{array}$ & $\begin{array}{c}-0.22 \\
0.23 \\
-0.25\end{array}$ & $\begin{array}{l}0.02 \\
0.01 \\
0.02\end{array}$ & $\begin{array}{l}0.02 \\
0.00 \\
0.03\end{array}$ & $\begin{array}{l}0.11 \\
0.02 \\
0.03\end{array}$ & $\begin{array}{l}-0.02 \\
-0.05 \\
-0.03\end{array}$ & 1 \\
\hline
\end{tabular}

Notes: Posteriors reported in bold were subject to a sign restriction. The respective sign can be inferred from the reported value of the posterior. 


\section{B Augmented Dickey Fuller tests}

Table A3: Augmented Dickey-Fuller tests

\begin{tabular}{llccrrr}
\hline & & Intercept & Trend & $t$-stat. & $5 \% \mathrm{CV}$ & $p$-value \\
\hline Copper & Level & yes & no & -1.11 & -2.9 & 0.71 \\
price & 1st Diff & no & no & -3.71 & -1.95 & 0 \\
\hline Fed funds & Level & no & no & -1.5 & -1.95 & 0.13 \\
rate & 1st Diff & no & no & -2.97 & -1.95 & 0 \\
\hline \multirow{2}{*}{ Money } & Level & yes & yes & 3.47 & -3.47 & 1 \\
& 1st Diff & yes & no & -3.2 & -2.9 & 0.02 \\
\hline Output & Level & no & no & -3.98 & -1.95 & 0 \\
gap & 1st Diff & no & no & -6.34 & -1.95 & 0 \\
\hline \multirow{2}{*}{ Exchange } & Level & yes & yes & -1.77 & -3.47 & 0.71 \\
rate & 1st Diff & yes & no & -4.37 & -2.9 & 0 \\
\hline \multirow{2}{*}{ CPI } & Level & yes & yes & -2.53 & -3.47 & 0.31 \\
& 1st Diff & yes & yes & -5.29 & -3.47 & 0 \\
\hline
\end{tabular}

Notes: All tests have been carried out with trends and intercept where the graphs in section 4 suggested their relevance, and removed when they turned out insignificant in the Dickey Fuller regression. The tests in first differences were carried out with the log differenced series as this corresponds to the series eventually included in out estimation for most variables. The exception is the output gap, where logs cannot be taken because of negative values. All results refer to a test with 4 lags of the variable for consistency with the main analysis. 